\title{
Effects of resveratrol on P-glycoprotein and cytochrome P450 3A in vitro and on pharmacokinetics of oral saquinavir in rats
}

This article was published in the following Dove Press journal:

Drug Design, Development and Therapy

I5 November 2016

Number of times this article has been viewed

\author{
Jiapeng $L i^{1,2}$ \\ Yang Liu ${ }^{2}$ \\ Jingru Zhang ${ }^{1,2}$ \\ Xiaotong $\mathrm{Yu}^{1,2}$ \\ Xiaoling Wang' \\ Libo Zhao' \\ 'Department of Pharmacy, Beijing \\ Children's Hospital, Capital Medical \\ University, ${ }^{2}$ Department of Pharmacy \\ Administration and Clinical Pharmacy, \\ School of Pharmaceutical Sciences, \\ Peking University, Beijing, People's \\ Republic of China
}

Background: The intestinal cytochrome P450 3A (CYP 3A) and P-glycoprotein (P-gp) present a barrier to the oral absorption of saquinavir (SQV). Resveratrol (RESV) has been indicated to have modulatory effects on P-gp and CYP 3A. Therefore, this study was to investigate the effects of RESV on P-gp and CYP 3A activities in vitro and in vivo on oral SQV pharmacokinetics in rats.

Methods: In vitro, intestinal microsomes were used to evaluate RESV effect on CYP 3A-mediated metabolism of SQV; MDR1-expressing Madin-Darby canine kidney (MDCKIIMDR1) cells were employed to assess the impact of RESV on P-gp-mediated efflux of SQV. In vivo effects were studied using 10 rats randomly assigned to receive oral SQV $(30 \mathrm{mg} / \mathrm{kg})$ with or without RESV (20 mg/kg). Serial blood samples were obtained over the following $24 \mathrm{~h}$. Concentrations of SQV in samples were ascertained using high-performance liquid chromatography-tandem mass spectrometry analysis.

Results: RESV (1-100 $\mu \mathrm{M})$ enhanced residual SQV (\% of control) in a dose-dependent manner after incubation with intestinal microsomes. RESV $(1-100 \mu \mathrm{M})$ reduced the accumulation of SQV in MDCKII-MDR1 cells in a concentration-dependent manner. A double peaking phenomenon was observed in the plasma SQV profiles in rats. The first peak of plasma SQV concentration was increased, but the second peak was reduced by coadministration with RESV. The mean $\mathrm{AUC}_{0-\infty}$ of SQV was slightly decreased, with no statistical significance probably due to the high individual variation.

Conclusion: RESV can alter the plasma SQV concentration profiles, shorten the $\mathrm{T}_{\max }$ of SQV. RESV might also cause a slight decrease tendency in the SQV bioavailability in rats.

Keywords: resveratrol, saquinavir, P-glycoprotein, CYP 3A, pharmacokinetic

\section{Introduction}

The standard treatment for the human immunodeficiency virus (HIV)/acquired immunodeficiency disease recommended by the World Health Organization includes at least three drugs in combination: two nucleoside reverse transcriptase inhibitors and one protease inhibitor (PI) or non-nucleoside reverse transcriptase inhibitor. This treatment is commonly termed highly active antiretroviral therapy. ${ }^{1}$ Saquinavir (SQV), as with other PIs, exerts its pharmacological activities by binding to the active site of viral protease enzyme, leading to the formation of immature virus particles. Although SQV is highly effective in blocking HIV-1 infection, SQV efficacy in clinical practice is limited, mainly due to its low and highly variable oral bioavailability, which is $\sim 4 \%$ with a coefficient of variation $(\mathrm{CV})>100 \%{ }^{2,3}$ Multiple factors contribute to the low oral bioavailability of SQV, including poor solubility characteristics, extensive first
Correspondence: Xiaoling Wang; Libo Zhao

Department of Pharmacy, Beijing Children's Hospital, Capital Medical University, 56 Nanlishi Road, Xicheng District, Beijing 100045, People's Republic of China Tel +86 I0 596I 6380; +86 I0 596I 6379 Fax +861059616380 Email eyjdb6380@I63.com; lb.zhao@I63.com 
pass metabolism and P-glycoprotein (P-gp) transport. After oral administration, $\mathrm{SQV}$ is extensively metabolized before systemic absorption by cytochrome P450 3A (CYP 3A) in the small intestine. ${ }^{4}$ In addition, SQV is a substrate for P-glycoprotein (P-gp) transporters with high affinity. ${ }^{5}$ The P-gp on intestine epithelia actively extrudes SQV from enterocytes back into the intestinal lumen, leading to a significant reduction in systematic plasma drug levels. ${ }^{5}$ Thus, coadministration of SQV with drug or diet that may inhibit or induce CYP 3A or/and P-gp activities should be viewed with caution.

Resveratrol (RESV) is a kind of stilbenes mainly found in red grapes, berries, and peanuts. ${ }^{6}$ RESV and its potential health benefits have attracted increasing interest since red wine consumption was found to be associated with low incidence of cardiovascular disease in the French despite a high-fat diet, which is popularly known as the "French paradox" phenomenon. ${ }^{7,8}$ During the past few years, RESV has been reported to exert various beneficial pharmacological effects, such as anti-inflammatory, ${ }^{9}$ anti-atherogenic, ${ }^{10}$ and anticarcinogenic ${ }^{11}$ activities. In addition, RESV exhibits antiHIV-1 activity. ${ }^{12}$ Recent results suggest a synergistic inhibition of HIV-1 by the combination of RESV and decitabine. ${ }^{13}$

Given its multiple beneficial pharmacological effects, introducing RESV as a supplemental agent into HIV-1 therapy seems reasonable. However, RESV has been indicated to modulate P-gp and CYP 3A activities, ${ }^{14,15}$ suggesting it may alter the pharmacokinetics (PK) or bioavailability of concomitant drugs that are P-gp or/and CYP 3A substrates, such as SQV. Whether, and to what extent, RESV influences intestinal P-gp-mediated efflux or CYP 3A-mediated

A

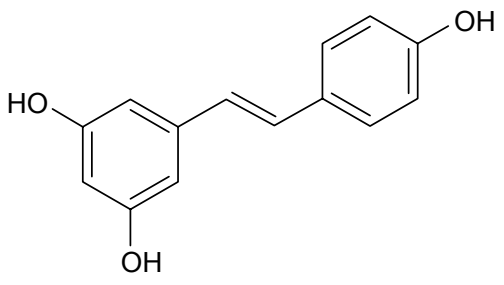

Figure I Chemical structures of resveratrol (A) and saquinavir (B). metabolism of SQV remains unclear. To our knowledge, no data are available concerning the impacts of RESV on the PK of SQV. Therefore, we conducted this study to investigate the effects of RESV on P-gp and CYP 3A activities and its impacts on the PK of SQV in rats.

\section{Materials and methods \\ Chemicals and reagents}

RESV (purity $>98 \%$ ) was purchased from FeiYu Biotechnology Corporation (Nantong, People's Republic of China). SQV was purchased from USP (Rockville, MD, USA). Chemical structures of RESV and SQV are shown in Figure 1. Pooled Sprague-Dawley rat (male) intestine microsomes were obtained from Xenotech LLC (Kansas City, KS, USA). Verapamil (VER) fluid injection (50 mL/branch) was obtained from HeFeng Pharmaceutical Co. Ltd (Shanghai, People's Republic of China). BCA Protein Assay Kit was purchased from Solarbio (Beijing, People's Republic of China). Ketoconazole (KET) (purity $>99 \%$ ) was purchased from the National Institutes for Food and Drug Control (Beijing, People's Republic of China). Dulbecco's Modified Eagle's Medium was from Gibco (Shanghai, People's Republic of China). Phosphatebuffered saline (PBS) and other reagents or solvents used were commercially available and of reagent grade.

\section{Animals}

Male Sprague-Dawley rats were purchased from the Academy of Military Medical Sciences (Beijing, People's Republic of China). Rats were housed in well-ventilated cages at room temperature $\left(24^{\circ} \mathrm{C} \pm 2^{\circ} \mathrm{C}\right)$ and $40 \%-60 \%$ relative humidity. Rats were kept on a $12 \mathrm{~h}$ night cycle (lights on from

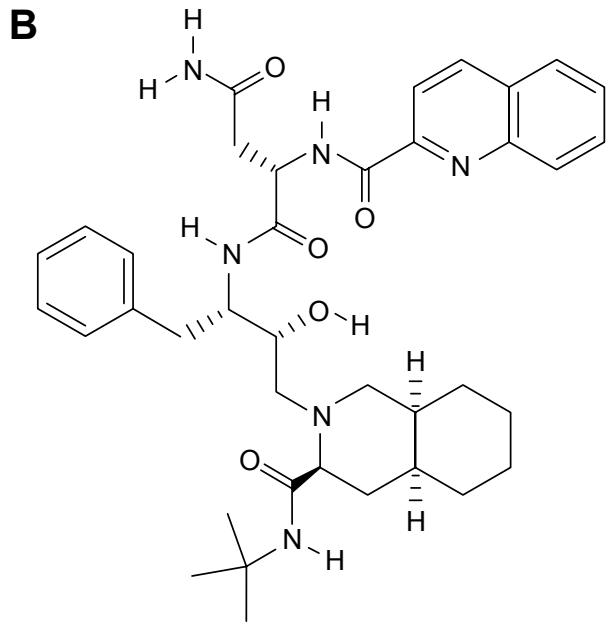


6 am to $6 \mathrm{pm}$ ). The animals were housed with free access to laboratory food and water ad libitum. Rats weighing 300-350 g (8-9 weeks old) were used in the PK study.

\section{In vitro metabolism experiment}

An in vitro experiment was conducted to assess the effect of RESV on intestinal CYP 3A-mediated metabolism of SQV. The procedures used are similar to previously reported methods. ${ }^{16,17}$ All incubations were performed in triplicate in $100 \mu \mathrm{L}$ of $100 \mathrm{mM}$ PBS (pH 7.4) containing $1 \mathrm{mM}$ nicotinamide adenine dinucleotide phosphate, $0.8 \mathrm{mg} / \mathrm{mL}$ intestinal microsomal protein and modulator $(10 \mu \mathrm{M} \mathrm{KET}$, or 1,10 , or $100 \mu \mathrm{M}$ RESV). The microsomes (replaced with equal volume of buffer in the control group) and KET or RESV were mixed and incubated at $37^{\circ} \mathrm{C}$ for $5 \mathrm{~min}$. Nicotinamide adenine dinucleotide phosphate was then added to initiate the reaction, and the mixture further incubated at $37^{\circ} \mathrm{C}$ for $15 \mathrm{~min}$. The reaction was terminated by the addition of $100 \mu \mathrm{L}$ ice-cold acetonitrile. Residual SQV was measured with the high-performance liquid chromatography tandem mass spectrometry (HPLC-MS/MS) analysis method described in the drug assay section below.

\section{In vitro cell accumulation experiment}

Cell accumulation experiment to assess the effect of RESV on P-gp mediated efflux of SQV. MDR1-expressing MadinDarby canine kidney (MDCKII-MDR1) cells were kindly provided by Prof Su Zeng. MDCKII-MDR1 cells were cultured in Dulbecco's Modified Eagle's culture Medium supplemented with 10\% fetal bovine serum (Gibco, USA), 100 units $/ \mathrm{mL}$ penicillin, and $100 \mathrm{mg} / \mathrm{mL}$ streptomycin. Cells were incubated at $37^{\circ} \mathrm{C}$ and $5 \% \mathrm{CO}_{2}$ atmosphere.

MDCKII-MDR1 cells were incubated with $50 \mu \mathrm{M}$ SQV in the absence or presence of various concentrations $(1,10$, 33 , and $100 \mu \mathrm{M})$ of RESV, the vehicle $(0.5 \%$ dimethylsulfoxide), or the positive control (50 $\mu \mathrm{M}$ VER) at $37^{\circ} \mathrm{C}$ for $4 \mathrm{~h}$. Cell viability was assessed through a 3-(4,5-dimethyl-2thiazolyl)-2,5-diphenyl-2H-tetrazolium bromide assay. ${ }^{18}$ Results showed that agents at concentrations adopted in this study did not exert significant damage on MDCKII-MDR1 cell variability. After $4 \mathrm{~h}$ incubation, cells were washed with cold PBS, suspended in $1 \mathrm{~mL}$ distilled water, and then collected into a tube. Cells in each tube were broken using an ultrasonic cell disruption system at $0^{\circ} \mathrm{C}$, and centrifuged $\left(13,400 \times g\right.$ for $5 \mathrm{~min}$ at $\left.4^{\circ} \mathrm{C}\right)$. The supernatant fraction was then transferred into a tube and frozen at $-20^{\circ} \mathrm{C}$ until analysis. The amount of protein in cells was measured using a BCA
Protein Assay Kit (Solarbio). The intracellular accumulation of SQV was quantified as the concentration ratio $(\mu \mathrm{g} / \mathrm{mg}$ protein), which was calculated by dividing the apparent uptake amount of SQV by protein content.

\section{In vivo PK experiment}

An in vivo experiment was conducted to assess the effects of RESV on SQV PK profiles in rats. The study protocol was approved, and adhered to the guidelines of the Animal Ethics Committee of Beijing Children's Hospital. We designed the PK study based on previously reported SQV in vivo studies. ${ }^{19,20}$ Rats were fasted for $12 \mathrm{~h}$ prior to experiments with free access to water. They were then randomized into two groups: a control group (SQV $30 \mathrm{mg} / \mathrm{kg}$, oral, aqueous suspension) and a RESV treatment group (SQV $30 \mathrm{mg} / \mathrm{kg}$ plus RESV $20 \mathrm{mg} / \mathrm{kg}$, oral, aqueous suspension). SQV was suspended in solvent (20\% ethanol, $30 \%$ propylene glycol, and $50 \%$ saline) at a concentration of $6 \mathrm{mg} / \mathrm{mL}$; RESV was suspended in saline with 30\% polyethylene glycol 400 at $20 \mathrm{mg} / \mathrm{mL}$ concentration. Each conscious animal was orally administrated an appropriate volume of suspension $(30 \mathrm{mg} /$ $\mathrm{kg} \mathrm{SQV}$ or $30 \mathrm{mg} / \mathrm{kg} \mathrm{SQV}+20 \mathrm{mg} / \mathrm{kg}$ RESV). Blood samples were taken from the posterior orbital venous plexus into heparinized Eppendorf tubes at 0, 0.25, 0.5, 1, 2, 4, 8, 12, and $24 \mathrm{~h}$ after drug administration. Rats were given food $4 \mathrm{~h}$ after blood samples were obtained. Blood samples were immediately centrifuged and the obtained plasma samples were stored at $-20^{\circ} \mathrm{C}$ until the time for LC-MS/MS analysis.

\section{Drug assay}

We used a validated HPLC-MS/MS analysis method ${ }^{21}$ to measure the concentrations of SQV in samples from the metabolism study, cell accumulation study, and PK study. Briefly, ritonavir was selected as the internal standard. The internal standard $(200 \mu \mathrm{L}, 20 \mathrm{ng} / \mathrm{mL})$ was first added into the $20 \mu \mathrm{L}$ buffer sample or $50 \mu \mathrm{L}$ plasma sample prior to further extraction with $3 \mathrm{~mL}$ methyl tert-butyl ether. The upper layer $(2.8 \mathrm{~mL})$ was carefully transferred into another clean tube and then evaporated to dryness at $40^{\circ} \mathrm{C}$ under a gentle stream of nitrogen. The dry residue was reconstituted with $200 \mu \mathrm{L}$ mobile phase $\left(\mathrm{CH}_{3} \mathrm{CN} / \mathrm{H}_{2} \mathrm{O}, 76.65: 23.35\right.$ [v/v], containing 0.2 $\left.\mathrm{mM} \mathrm{NH}_{4} \mathrm{COOH}\right)$. After vortex mixing, the extracted samples were centrifuged $\left(13,400 \times g\right.$ for $5 \mathrm{~min}$ at $\left.4^{\circ} \mathrm{C}\right)$ and the supernatant $(10 \mu \mathrm{L})$ was injected into the HPLC/MS-MS system.

The HPLC/MS-MS analysis was carried out on a Restek C18 (150×2.1 mm ID) column (Bellefonte, PA, USA) with the mobile phase at a flow rate of $300 \mu \mathrm{L}$ per minute. 
SQV (retention time, $3.63 \mathrm{~min}$ ) and ritonavir (retention time, $2.67 \mathrm{~min}$ ) were analyzed by fragmentation of the parent compound and quantification of resulting fragments. The monitoring ions of SQV and ritonavir were $m / z$ 671.4/570.4 and $m / z 721.4 / 296.2$, respectively. The lower limit of quantification of SQV was $1 \mathrm{ng} / \mathrm{mL}$ in extracted samples. The precision and accuracy of the quality control samples at three concentration levels (low, middle, and high: 3, 50, and $150 \mathrm{ng} / \mathrm{mL}$, respectively) were within $15 \%$ relative standard deviation and $15 \%$ relative error, respectively.

\section{PK analysis}

The PK parameters of SQV in plasma were determined by noncompartmental method using WinNonlin version 6.4 (Pharsight Corporation, Mountain View, CA, USA). The area under the plasma concentration-time curves (AUC) from time 0 to $24 \mathrm{~h}\left(\mathrm{AUC}_{0-\mathrm{t}}\right)$ was determined using the linear trapezoidal rule. The terminal elimination half-life $\left(t_{1 / 2}\right)$ was calculated as $\ln 2 / \lambda_{z}$ using the slope $\left(\lambda_{z}\right)$ from a linear regression analysis of the terminal phase of the plasma concentration-time curve on a semilog scale. The AUC from time zero to infinity $\left(\mathrm{AUC}_{0-\infty}\right)$ was calculated using the linear trapezoidal rule, formulated as $\mathrm{AUC}_{0-\infty}=\mathrm{AUC}_{0-\mathrm{t}}+\mathrm{C}_{\mathrm{t}} / \lambda_{\mathrm{z}}$, where $C_{t}$ was the last measured concentration in plasma. The apparent systemic clearance $(\mathrm{CL} / \mathrm{F})$ was calculated as: $\mathrm{CL} / \mathrm{F}=\operatorname{dose} / \mathrm{AUC}_{0-\infty}$.

\section{Statistical analysis}

The data for analysis of variance and Student's $t$-test were normally distributed as assessed by Shapiro-Wilk test. Oneway analysis of variance with Duncan's multiple range test was used for statistical comparisons for the in vitro studies. For the in vivo study, $\mathrm{AUC}_{0-\infty}, \mathrm{C}_{\max }, \mathrm{t}_{1 / 2}, \mathrm{CL} / \mathrm{F}$, and $\mathrm{MRT}_{0-\infty}$ were transformed into a logarithmic form and analyzed with independent-samples Student's $t$-test; the time to $\mathrm{C}_{\max }$, $\mathrm{T}_{\max }$, was analyzed with Wilcoxon rank sum test. Statistical analyses were done with IBM SPSS Statistics for Windows, version 20.0 (IBM Corp, Armonk, NY, USA). A $P$-value of $<0.05$ was considered significant.

\section{Results}

\section{RESV inhibits intestinal CYP 3A-mediated metabolism of SQV}

The effects of RESV at various concentrations on the residual SQV presence after 15 min of metabolism are shown in Figure 2. The residual SQV in $0 \mu \mathrm{M}$ RESV group $(61.5 \%$ of control) was significantly lower than those in control (without CYP 3A) and KET (CYP 3A inhibitor) group $(P<0.01)$. Residual SQV increased with RESV in a dose-dependent

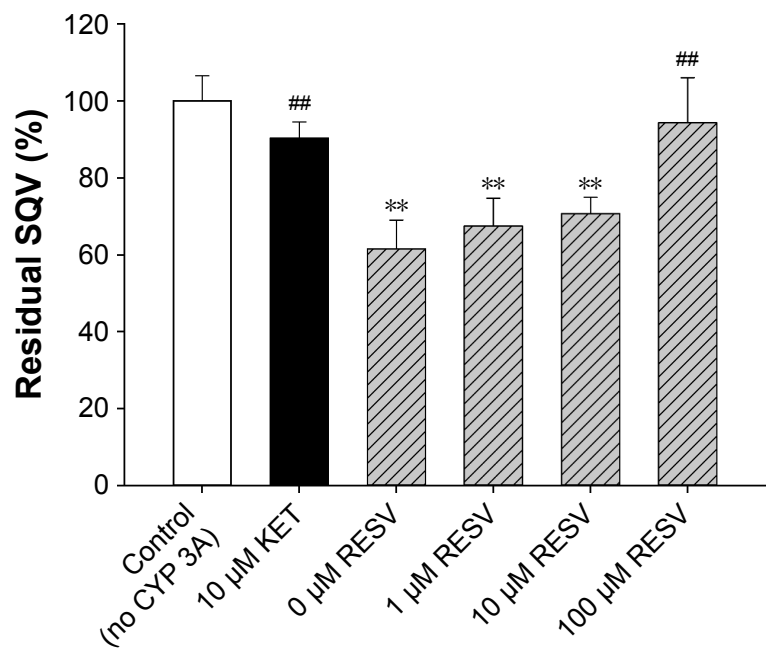

Figure 2 Effect of RESV on the intestinal CYP 3A mediated metabolism of SQV. Notes: Data are presented as mean $\pm S D, n=3$. Significant differences were determined by one-way ANOVA with Duncan's multiple range test, $* * P<0.01$ compared with the control group (no CYP $3 A$ ); ${ }^{\# P}<0.0$ l compared with the $0 \mu M$ RESV group.

Abbreviations: ANOVA, analysis of variance; CYP 3A, cytochrome P450 3A; RESV, resveratrol; SD, standard deviation; SQV, saquinavir; KET, ketoconazole.

manner, with $67.5 \%, 70.7 \%$, and $94.3 \%$ of control in the presence of 1,10 , and $100 \mu \mathrm{M}$ RESV, respectively, suggesting a concentration-dependent inhibitory effect on intestinal CYP 3A-mediated SQV metabolism.

\section{RESV stimulates P-gp mediated efflux of SQV}

The effects of RESV at various concentrations on accumulations of SQV in MDCKII-MDR1 cells are shown in Figure 3.

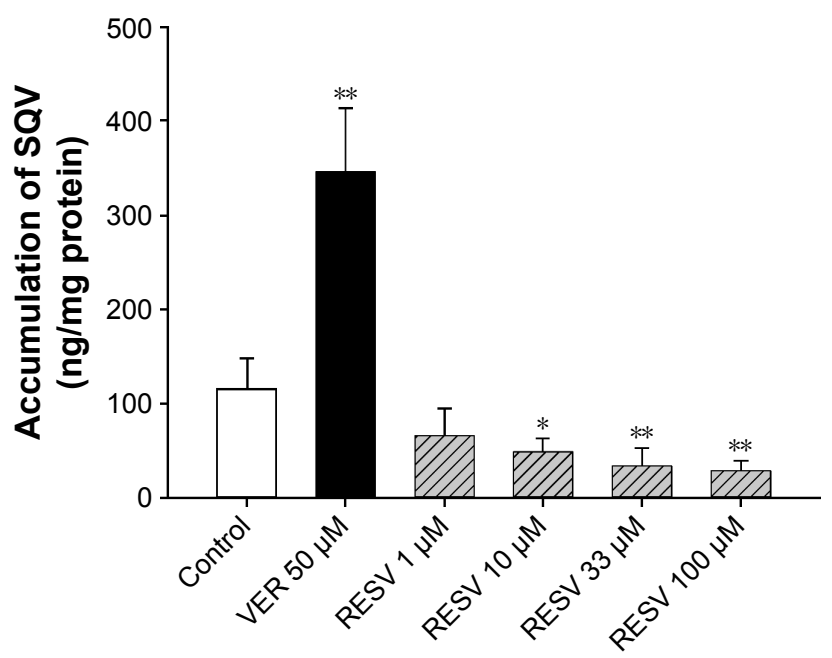

Figure 3 Effect of RESV on the accumulation of SQV in MDCKII-MDRI cells. Notes: Data are presented as mean $\pm S D, n=4$. Significant differences were determined by one-way ANOVA with Duncan's multiple range test, $* P<0.05$; $* * P<0.0$ l compared with the control group.

Abbreviations: ANOVA, analysis of variance; MDCK, Madin-Darby canine kidney; RESV, resveratrol; SD, standard deviation; SQV, saquinavir; VER, verapamil. 


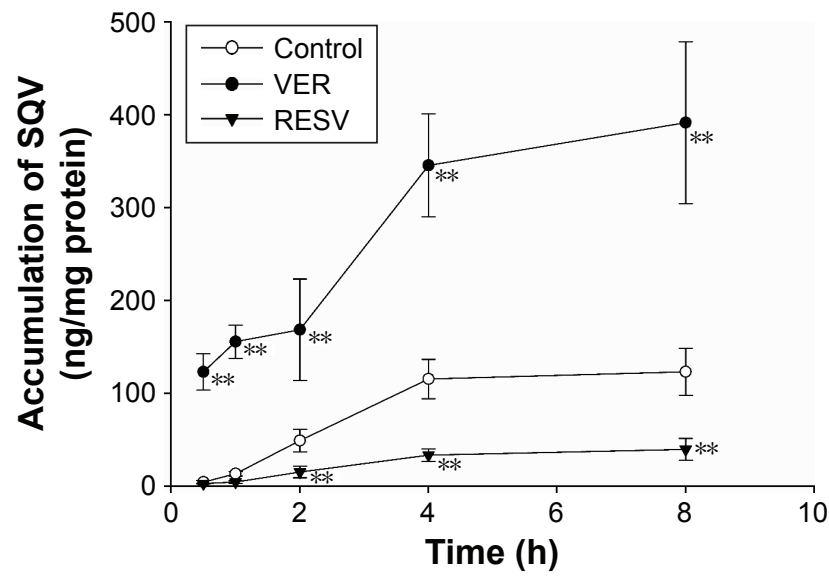

Figure 4 Effect of RESV on the accumulation of SQV in MDCKII-MDRI cells. Notes: Data are presented as mean $\pm S D, n=4$. Significant differences were determined by one-way ANOVA with Duncan's multiple range test, ${ }^{*} * P<0.0$ I compared with the control group.

Abbreviations: ANOVA, analysis of variance; MDCK, Madin-darby canine kidney; RESV, resveratrol; SD, standard deviation; SQV, saquinavir; VER, verapamil.

The treatment of $50 \mu \mathrm{M}$ VER, a P-gp inhibitor served as a positive control; intracellular accumulation of SQV increased by nearly $200 \%$, implying the experiment provides a reliable in vitro model for assessing P-gp regulatory effects. Significant decreases of SQV intracellular concentration were observed in the presence of $10(P<0.05), 33(P<0.01)$, and $100 \mu \mathrm{M}$ RESV $(P<0.01)$, a percent change with RESV dose of $-58.1 \%,-71.2 \%$, and $-75.5 \%$, respectively. This finding indicates that RESV stimulates P-gp-mediated efflux of SQV in a concentration-dependent manner.

The time profiles of the intracellular accumulation of SQV in the presence of RESV $(33 \mu \mathrm{M})$ or VER $(50 \mu \mathrm{M})$ are illustrated in Figure 4. The accumulation time profile of SQV reached steady state at $4 \mathrm{~h}$ after initiation of incubation. Compared with controls, intracellular concentrations of SQV decreased $(P<0.01)$ in RESV treatments continuously after $2 \mathrm{~h}$ co-incubation, indicating a time-dependent stimulatory effect on the P-gp-mediated efflux of SQV.

\section{RESV alters SQV PK profiles in rats}

In vivo plasma concentration-time profiles of SQV in rats after receiving a single oral dose of SQV (30 mg/ $\mathrm{kg}$ ), with or without RESV (20 mg/kg), are shown in Figure 5. Wide interindividual variability was observed. In addition, a double peak phenomenon was observed, with the first peak in plasma levels reached at $\sim 0.5$ (control group) or $0.25 \mathrm{~h}$ (RESV treatment group), and the second peak at $\sim 4 \mathrm{~h}$ (both groups). The profile of plasma SQV concentrations was significantly affected by coadministration of RESV. The first peak in the plasma drug profile in RESV treatment group was significantly higher than that in the control group, while

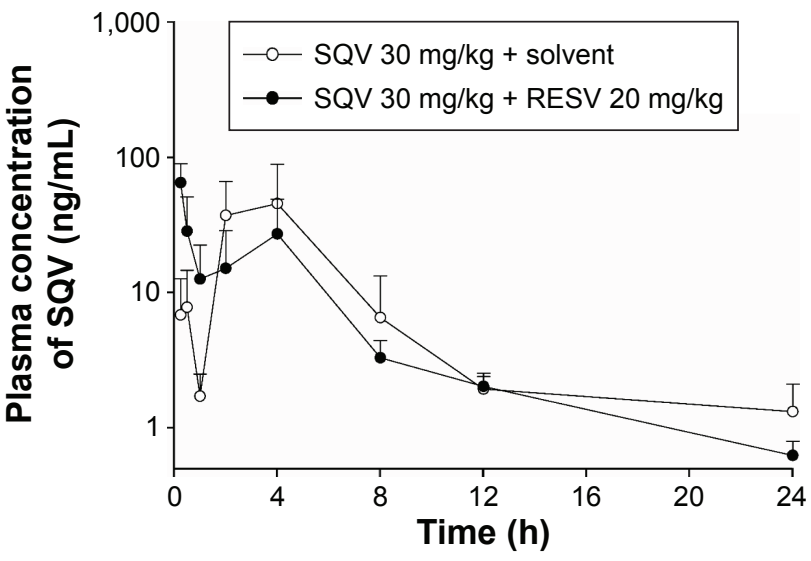

Figure 5 Plasma concentration-time curves of SQV.

Notes: Mean plasma concentration-time curves of SQV after a single oral dose administration of SQV $(30 \mathrm{mg} / \mathrm{kg})$ with or without oral coadministration of RESV $(20 \mathrm{mg} / \mathrm{kg})$. Each point represents the mean $\pm S D, n=5$.

Abbreviations: RESV, resveratrol; SD, standard deviation; SQV, saquinavir.

the second one was significantly lower. The SQV plasma concentration curve declined more rapidly in the presence of RESV. (Composite curves graphed plasma SQV profiles for the control and treatment groups were displayed in Supplementary materials.)

The PK parameters of SQV are summarized in Table 1. Oral coadministration of RESV $(20 \mathrm{mg} / \mathrm{kg})$ decreased mean $\mathrm{AUC}_{0-\infty}$ of $\mathrm{SQV}$ by $\sim 31 \%$, but this change had no statistical significance $(P>0.05)$. The mean $\mathrm{CL} / \mathrm{F}$ of SQV was increased by $\sim 51 \%$ with no statistical significance $(P>0.05)$. The $\mathrm{T}_{\max }$ of SQV was significantly shortened (from $\sim 4 \mathrm{~h}$ to $\sim 0.25 \mathrm{~h}$, $P<0.01$ ) by coadministration with RESV, but $\mathrm{C}_{\text {max }}$ was not significantly affected $(P>0.05)$.

\section{Discussion}

This study includes both in vitro and in vivo experiments to explore the interaction between RESV and SQV. In vitro,

Table I Pharmacokinetic parameters of SQV after an oral dose of $30 \mathrm{mg} / \mathrm{kg}$ with or without oral coadministration of RESV $20 \mathrm{mg} / \mathrm{kg}$

\begin{tabular}{|c|c|c|}
\hline \multirow[t]{2}{*}{ Parameter (unit) } & \multicolumn{2}{|c|}{ SQV (30 mg/kg, oral) } \\
\hline & Control & RESV (20 mg/kg, oral) \\
\hline$A \cup C_{0-\infty}(\mathrm{ng} \cdot \mathrm{h} / \mathrm{mL})$ & $258.06 \pm 126.79$ & $177.92 \pm 90.52$ \\
\hline $\mathrm{C}_{\max }(\mathrm{ng} / \mathrm{mL})$ & $59.42 \pm 35.23$ & $64.66 \pm 24.37$ \\
\hline $\mathrm{T}_{\max }(\mathrm{h})$ & $4(0)$ & $0.25(0)^{* *}$ \\
\hline$t_{1 / 2}(h)$ & $6.34 \pm 1.73$ & $5.77 \pm 0.56$ \\
\hline $\mathrm{MRT}_{0-\infty}(\mathrm{h})$ & $6.73 \pm 1.95$ & $5.60 \pm 1.11$ \\
\hline $\mathrm{CL} / \mathrm{F}(\mathrm{L} / \mathrm{h} / \mathrm{kg})$ & $134.9 \mid \pm 53.90$ & $203.67 \pm 87.17$ \\
\hline $\mathrm{RB}^{\mathrm{a}}(\%)$ & 100 & 68.95 \\
\hline
\end{tabular}

Notes: Data are presented as mean $\pm S D$ except for $T_{\max }$, for which the median (interquartile range) is reported. $n=5$ for each group. $* * P<0.01$ compared with

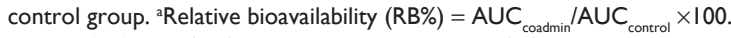
Abbreviations: $A \cup C$, area under the curve; $C L / F$, clearance; $h$, hours; max, maximum; RESV, resveratrol; SD, standard deviation; SQV, saquinavir; $t_{1 / 2}$, terminal elimination half-life; MRT, mean residence time. 
RESV inhibited metabolism of SQV by rat intestinal CYP 3A, which is fairly consistent with the findings of previous studies. ${ }^{14,15,22,23}$ On the other hand, RESV showed stimulatory effects on the P-gp-mediated efflux of SQV. In vivo, RESV led to a greater peak in plasma SQV in the first hour after dosing, but a decreased level of SQV relative to the control after $2 \mathrm{~h}$.

In order to investigate the impact of RESV on intestinal P-gp-mediated efflux, another major barrier for SQV absorption, we evaluated the accumulation of SQV in MDCKII-MDR1 cells in the presence or absence of RESV. MDCKII-MDR1 cells are MDCK cells transfected with the human MDR1 gene; they express P-gp but do not express other efflux transporters, such as BCRP and MRP2. ${ }^{24}$ MDCKII-MDR1 cells are commonly employed as an in vitro model for intestinal epithelium. ${ }^{25-27}$ Results in the accumulation study suggest that RESV stimulates the P-gp-mediated efflux of SQV.

Findings of the effect of RESV on P-gp from previous studies are controversial. For example, Choi et al found that RESV significantly reduced rhodamine 123 efflux via P-gp in MCF-7/ADR cells that overexpress P-gp, and significantly increased the drug exposure of orally administered nicardipine in rats. ${ }^{28}$ In contrast, Yang et al reported that RESV exerted a stimulatory effect on $\mathrm{P}$-gp, resulting in a reduction of cyclosporine oral bioavailability in rats. ${ }^{15}$ These findings suggest that RESV exerts stimulatory/inhibitory effects on P-gp depending on the substrate. It seems likely that the substrate-dependent modulation results from complicated interactions between substrates involving P-gp substrate binding sites. The binding sites for any particular P-gp substrate may be the same or distinct from those for another substrate. ${ }^{24,29-32}$ This may lead to competition between substrates that bind identical sites or to a positive cooperative effect between substrates that bind different sites. ${ }^{32,33}$ In this case, the latter could explain the stimulation of RESV on P-gp-mediated efflux of SQV.

In the PK study, rats were used as the animal model mainly due to the similarity in basic intestinal structures and physiology of rats and humans. ${ }^{34}$ We observed a high interindividual variability in the SQV plasma concentrationtime profiles, which is generally consistent with previous PK studies in rats. ${ }^{35,36}$ Moreover, we noticed a double peak phenomenon in plasma SQV profiles in the presence and absence of RESV. Similar double peaking phenomena were also docu-

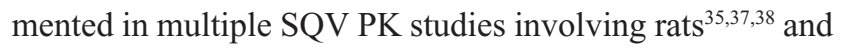
humans. ${ }^{39-41}$ Several physiological mechanisms can generate the double peaking phenomenon, including enterohepatic recycling, gastric emptying, small intestinal transit, and site-specific absorption. ${ }^{42}$ However, since no double peak has been observed after intravenous dosing of SQV, $35,39,40$ the second peak cannot be explained by enterohepatic recycling. Similarly, because the increase phase of SQV plasma profiles started earlier than food intake, it seems unlikely that gastric emptying plays an important role. Here, we speculate that the double peak phenomenon mainly results from site-specific intestinal absorption. SQV is one of the class II compounds categorized in Biopharmaceutics Classification System, with low solubility and high permeability. ${ }^{43}$ This property suggests that dissolution is a rate-limiting step for the oral absorption of SQV. Thus, the second peak in the SQV plasma profiles can be due to the increase of SQV dissolution in the more acidic environment of the colon compared with ileum. ${ }^{44}$ In addition, the regional differences in P-gp expression and activity along the intestine may play a significant role in causing the double peak. ${ }^{45} \mathrm{P}$-gp levels increase progressively from proximal to distal region in human or rodent small intestine. ${ }^{43,46}$ The ileum region shows significantly higher $\mathrm{P}$-gp function than in other region. ${ }^{43}$ Therefore, we infer that after oral administration, SQV was absorbed rapidly in the proximal small intestine, and then it was transported back into the intestine lumen by $\mathrm{P}$-gp at the ileum, resulting in a rapid rise of plasma SQV levels initially, followed by a decrease. After that, absorption increased again at the colon where P-gp expression is lower, leading to a second peak in the plasma SQV levels.

Overall, the mean $\mathrm{AUC}_{0-\infty}$ of SQV was decreased by nearly $30 \%$ by coadministration with RESV, but this change had no statistical significance, which might be partially due to the high variation between individuals. The impact of RESV on SQV PK profiles can be attributed to the effects of RESV on intestinal CYP 3A and P-gp. The distribution of CYP 3A in the small intestine of rats is markedly different from that of P-gp. CYP 3A is one of the two most abundant P450 isoforms (the other one is CYP 2B1) in the duodenum and jejunum of rat intestines but it is not present in either the ileum or the colon. ${ }^{47}$ It is most likely that RESV inhibits the CYP $3 \mathrm{~A}$ mediated metabolism of SQV, leading to an increase of SQV absorption in the proximal intestine. In contrast, RESV reduces the absorption of $\mathrm{SQV}$ in distal intestine (ileum and colon) by stimulating P-gp-mediated efflux of SQV. Overall, the positive effect of RESV on the absorption of SQV in the proximal intestine is offset by its negative effect in the distal intestine, eventually resulting in a nonsignificant change in the SQV oral bioavailability.

\section{Conclusion}

This study demonstrates that RESV can inhibit intestinal CYP 3A-mediated SQV metabolism and stimulate 
P-gp-mediated efflux of SQV. RESV can alter the SQV plasma concentration profiles and shorten the $\mathrm{T}_{\text {max }}$ of $\mathrm{SQV}$. RESV also leads to a decrease tendency in the SQV oral bioavailability, but this change has no statistical significance probably because of the high individual variation. Further clinical investigations are required to assess the benefit and risk of the concomitant use of SQV with RESV.

\section{Acknowledgments}

We gratefully acknowledge the assistance of Prof Su Zeng and Dr Xi Chen.

This study was funded by a grant from the National Natural Science Foundation of China (No 81102877).

\section{Disclosure}

The authors report no conflicts of interest in this work.

\section{References}

1. WHO. Consolidation Guidelines on the Use of Antiretroviral Drugs for Treating and Preventing HIV Infection. Geneva, Switzerland. World Health Organization; 2013.

2. Kitchen VS, Skinner C, Ariyoshi K, et al. Safety and activity of saquinavir in HIV infection. Lancet. 1995;345(8955):952-955.

3. Noble S, Faulds D. Saquinavir. A review of its pharmacology and clinical potential in the management of HIV infection. Drugs. 1996;52(1): 93-112.

4. Fitzsimmons ME, Collins JM. Selective biotransformation of the human immunodeficiency virus protease inhibitor saquinavir by human smallintestinal cytochrome P4503A4 potential contribution to high first-pass metabolism. Drug Metab Dispos. 1997;25(2):256-266.

5. Kim AE, Dintaman JM, Waddell DS, Silverman JA. Saquinavir, an HIV protease inhibitor, is transported by P-glycoprotein. J Pharmacol Exp Ther. 1998;286(3):1439-1445.

6. Giovinazzo G, Ingrosso I, Paradiso A, De Gara L, Santino A. Resveratrol biosynthesis: plant metabolic engineering for nutritional improvement of food. Plant Foods Hum Nutr. 2012;67(3):191-199.

7. Sun AY, Simonyi A, Sun GY. The "French Paradox" and beyond: neuroprotective effects of polyphenols. Free Radic Biol Med. 2002;32(4): 314-318.

8. Criqui MH, Ringel BL. Does diet or alcohol explain the French paradox? Lancet. 1994;344(8939):1719-1723.

9. Frémont L. Biological effects of resveratrol. Life Sci. 2000;66(8): 663-673.

10. Fan E, Zhang L, Jiang S, Bai Y. Beneficial effects of resveratrol on atherosclerosis. J Med Food. 2008;11(4):610-614.

11. Jang M, Cai L, Udeani GO, et al. Cancer chemopreventive activity of resveratrol, a natural product derived from grapes. Science. 1997; 275(5297):218-220.

12. Zhang H-S, Zhou Y, Wu M-R, Zhou H-S, Xu F. Resveratrol inhibited Tat-induced HIV-1 LTR transactivation via NAD(+)-dependent SIRT1 activity. Life Sci. 2009;85(13-14):484-489.

13. Clouser CL, Chauhan J, Bess MA, et al. Anti-HIV-1 activity of resveratrol derivatives and synergistic inhibition of HIV-1 by the combination of resveratrol and decitabine. Bioorg Med Chem Lett. 2012;22(21): 6642-6646.

14. Chi Y-C, Lin S-P, Hou Y-C. A new herb-drug interaction of Polygonum cuspidatum, a resveratrol-rich nutraceutical, with carbamazepine in rats. Toxicol Appl Pharmacol. 2012;263(3):315-322.

15. Yang S-Y, Tsai S-Y, Hou Y-C, Chao P-DL. Inductive modulation on P-glycoprotein and cytochrome $3 \mathrm{~A}$ by resveratrol, a constituent of grapes. Food Chem. 2012;133(3):683-688.
16. Zhuang X, Shen G, Yuan M, Li H. Investigation of the pharmacokinetic interaction between ritonavir and CMDCK, a new non-nucleoside reverse transcriptase inhibitor. Drug Res (Stuttg). 2013;63(5):237-242.

17. Choi YH, Lee I, Lee MG. Effects of cysteine on metformin pharmacokinetics in rats with protein-calorie malnutrition: partial restoration of some parameters to control levels. J Pharm Pharmacol. 2008;60(2): 153-161.

18. Vellonen KS, Honkakoski P, Urtti A. Substrates and inhibitors of efflux proteins interfere with the MTT assay in cells and may lead to underestimation of drug toxicity. Eur J Pharm Sci. 2004;23(2):181-188.

19. Kim S-A, Kim S-W, Choi H-K, Han H-K. Enhanced systemic exposure of saquinavir via the concomitant use of curcumin-loaded solid dispersion in rats. Eur J Pharm Sci. 2013;49(5):800-804.

20. Vyas TK, Shahiwala A, Amiji MM. Improved oral bioavailability and brain transport of saquinavir upon administration in novel nanoemulsion formulations. Int J Pharm. 2008;347(1-2):93-101.

21. Liang G, Li N, Ma L, et al. Effect of quercetin on the transport of ritonavir to the central nervous system in vitro and in vivo. Acta Pharm. 2016; 66(1):97-107.

22. Piver B, Berthou F, Dreano Y, Lucas D. Differential inhibition of human cytochrome P450 enzymes by $\varepsilon$-viniferin, the dimer of resveratrol: comparison with resveratrol and polyphenols from alcoholized beverages. Life Sci. 2003;73(9):1199-1213.

23. Piver B, Berthou F, Dreano Y, Lucas D. Inhibition of CYP3A, CYP1A and CYP2E1 activities by resveratrol and other non volatile red wine components. Toxicol Lett. 2001;125(1):83-91.

24. Taub ME, Podila L, Ely D, Almeida I. Functional assessment of multiple P-glycoprotein (P-gp) probe substrates: influence of cell line and modulator concentration on P-gp activity. Drug Metab Dispos. 2005; 33(11):1679-1687.

25. Troutman MD, Thakker DR. Novel experimental parameters to quantify the modulation of absorptive and secretory transport of compounds by P-glycoprotein in cell culture models of intestinal epithelium. Pharm Res. 2003;20(8):1210-1224.

26. Soldner A, Benet LZ, Mutschler E, Christians U. Active transport of the angiotensin-II antagonist losartan and its main metabolite EXP 3174 across MDCK-MDR1 and Caco-2 cell monolayers. Br J pharmacol. 2000;129(6):1235-1243.

27. Liu Y, Zeng S. [Advances in the MDCK-MDR1 cell model and its applications to screen drug permeability]. Үaо Хие Хие Вао. 2008;43(6): 559-564. Chinese.

28. Choi J-S, Choi B-C, Kang KW. Effect of resveratrol on the pharmacokinetics of oral and intravenous nicardipine in rats: possible role of P-glycoprotein inhibition by resveratrol. Pharmazie. 2009;64(1):49-52.

29. Chufan EE, Kapoor K, Sim HM, et al. Multiple transport-active binding sites are available for a single substrate on human P-glycoprotein (ABCB1). PLoS One. 2013;8(12):e82463.

30. Pajeva IK, Sterz K, Christlieb M, Steggemann K, Marighetti F, Wiese M. Interactions of the multidrug resistance modulators tariquidar and elacridar and their analogues with P-glycoprotein. ChemMedChem. 2013; 8(10):1701-1713

31. Martinez L, Arnaud O, Henin E, et al. Understanding polyspecificity within the substrate-binding cavity of the human multidrug resistance P-glycoprotein. FEBS J. 2014;281(3):673-682.

32. Shapiro AB, Ling V. Positively cooperative sites for drug transport by P-glycoprotein with distinct drug specificities. Eur J Biochem. 1997; 250(1):130-137.

33. Chufan EE, Sim H-M, Ambudkar SV. Chapter three - molecular basis of the polyspecificity of P-glycoprotein (ABCB1): recent biochemical and structural studies. In: John DS, Toshihisa I, editors. Advances in Cancer Research. Academic Press; 2015:71-96.

34. Jain R, Duvvuri S, Kansara V, Mandava NK, Mitra AK. Intestinal absorption of novel-dipeptide prodrugs of saquinavir in rats. Int $J$ Pharm. 2007;336(2):233-240.

35. Buchanan CM, Buchanan NL, Edgar KJ, et al. Pharmacokinetics of saquinavir after intravenous and oral dosing of saquinavir: hydroxybutenyl-beta-cyclodextrin formulations. Biomacromolecules. 2008;9(1):305-313. 
36. Hirunpanich V, Murakoso K, Sato H. Inhibitory effect of docosahexaenoic acid (DHA) on the intestinal metabolism of midazolam: in vitro and in vivo studies in rats. Int J Pharm. 2008;351(1-2):133-143.

37. Pathak SM, Musmade P, Dengle S, Karthik A, Bhat K, Udupa N. Enhanced oral absorption of saquinavir with methyl-beta-cyclodextrin preparation and in vitro and in vivo evaluation. Eur J Pharm Sci. 2010; 41(3):440-451.

38. Pathak SM, Kumar AR, Subramanian G, Udupa N. Development and validation of a reversed-phase liquid chromatographic method with fluorescence detection for the study of saquinavir pharmacokinetics in rat plasma. Anal Chim Acta. 2007;594(2):248-256.

39. Kupferschmidt HH, Fattinger KE, Ha HR, Follath F, Krähenbühl S. Grapefruit juice enhances the bioavailability of the HIV protease inhibitor saquinavir in man. Br J Clin Pharmacol. 1998;45(4):355-359.

40. Ha HR, Follath F, Bloemhard Y, Krähenbühl S. Determination of saquinavir in human plasma by high-performance liquid chromatography. J Chromatogr B Biomed Sci Appl. 1997;694(2):427-433.

41. Fröhlich M, Burhenne J, Martin-Facklam M, et al. Oral contraception does not alter single dose saquinavir pharmacokinetics in women. Br J Clin Pharmacol. 2004;57(3):244-252.
42. Davies NM, Takemoto JK, Brocks DR, Yanez JA. Multiple peaking phenomena in pharmacokinetic disposition. Clin Pharmacokinet. 2010;49(6):351-377.

43. Murakami T, Takano M. Intestinal efflux transporters and drug absorption. Expert Opin Drug Metab Toxicol. 2008;4(7):923-939.

44. Agoram B, Woltosz WS, Bolger MB. Predicting the impact of physiological and biochemical processes on oral drug bioavailability. $A d v$ Drug Deliv Rev. 2001;50(Suppl 1):S41-S67.

45. Wada S, Kano T, Mita S, et al. The role of inter-segmental differences in P-glycoprotein expression and activity along the rat small intestine in causing the double-peak phenomenon of substrate plasma concentration. Drug Metab Pharmacokinet. 2013;28(2):98-103.

46. Mouly S, Paine MF. P-glycoprotein increases from proximal to distal regions of human small intestine. Pharm Res. 2003;20(10):1595-1599.

47. Mitschke D, Reichel A, Fricker G, Moenning U. Characterization of cytochrome $\mathrm{P} 450$ protein expression along the entire length of the intestine of male and female rats. Drug Metab Dispos. 2008;36(6):1039-1045.
Drug Design, Development and Therapy

\section{Publish your work in this journal}

Drug Design, Development and Therapy is an international, peerreviewed open-access journal that spans the spectrum of drug design and development through to clinical applications. Clinical outcomes, patient safety, and programs for the development and effective, safe, and sustained use of medicines are the features of the journal, which

\section{Dovepress}

has also been accepted for indexing on PubMed Central. The manuscript management system is completely online and includes a very quick and fair peer-review system, which is all easy to use. Visit http://www.dovepress.com/testimonials.php to read real quotes from published authors.

Submit your manuscript here: http://www.dovepress.com/drug-design-development-and-therapy-journal 